\title{
Environmental challenges and traditional food practices: The indigenous Lundayeh of Long Pasia, Sabah, Borneo
}

\author{
Kavitha Ganesan @https://orcid.org/0000-0002-5248-8103 \\ Anantha Raman Govindasamy ${ }^{-h}$ htps://orcid.org/0000-0003-2467-2138 \\ Jane Wong Kon Ling Chttps://orcid.org/0000-0001-7350-3635 \\ Shaffarullah Abdul Rahman $\mathbb{C}$ htps://orcid.org/0000-0002-1804-818X \\ Kennedy Aaron Aguol @https://orcid.org/0000-0002-3311-9628 \\ Jamsari Hashim $\odot$ https://orcid.org/0000-0001-6145-846X \\ Bilcher Bala @ittps://orcid.org/0000-0002-4842-6145
}

Universiti Malaysia Sabah, Borneo

\begin{abstract}
In this paper we focus on the Lundayeh indigenous minority in Long Pasia, Sabah by examining how their traditional food practices help them navigate environmental challenges. Deforestation and logging threaten the very core of the Lundayeh identity because the community's livelihood as subsistence farmers depends on hunting as well as gathering forest resources. This paper argues that, despite the continuous challenges, Lundayeh food practices, albeit exercised in modified forms, provide an avenue to revisit past traditions in order for the community's indigeneity and sovereignty to survive and be safeguarded. The findings of this research project suggest that through hunting techniques, foraging, paddy cultivation, agricultural cooperative work, as well as religiously sensitive food adaptation practices, the Lundayeh's relationship with the land endures, which in turn, secures the community's indigenous identity.
\end{abstract}

Keywords: Lundayeh, indigenous minority, traditional food practices, deforestation, logging, hunting, paddy cultivation, Sabah, Borneo

eTropic: electronic journal of studies in the tropics publishes new research from arts, humanities, social sciences and allied fields on the variety and interrelatedness of nature, culture, and society in the tropics. Published by James Cook University, a leading research institution on critical issues facing the worlds' Tropics. Free open access, Scopus, Google Scholar, DOAJ, Crossref, Ulrich's, SHERPA/RoMEO, Pandora, ISSN 1448-2940. Creative Commons CC BY 4.0. Articles are free to download, save and reproduce. Citation: to cite this article include Author(s), title, eTropic, volume, issue, year, pages and DOI: http://dx.doi.org/10.25120/etropic.19.1.2020.3734 


\section{The Lundayeh community in Long Pasia}

$\mathrm{T}$

his article examines the Lundayeh minority in the state of Sabah, Malaysia, who are located in the northern part of Borneo, by specifically tracing the community's traditional food practices that both endure and contest rapid environmental challenges prevalent through deforestation and logging. Historically it should be noted that before territorial divisions were drawn between the British and Dutch colonial powers occupying the island of Borneo, the Lundayehs inhabited a borderless land area. Under colonialism they came to inhabit different administrative territories. The colonial territories eventually became independent nation-states thus placing them under the Malaysian, Bruneian, and Indonesian political regions. These divisions invariably affected the ethnic identification of the community: in Sabah they are known as Lundayeh; in Sarawak as Lun Bawang; in Brunei as Lun Bawang Murut; and in Kalimantan, Indonesia, as Dayak Lundayeh. Despite the different names accorded by state region, all linguistic and cultural elements remain the same and are shared by the Lundayehs as a whole (see Wong et al., 2007).

Although the Lundayehs are also found in the other three political units of Borneo (Sarawak, Brunei, and Kalimantan), this paper specifically focuses on those occupying the village of Long Pasia, which is a highland area situated at an altitude of 1,000 metres within the Sipitang District in Sabah. The word Long Pasia (spelt Lung Pa' Sia in Lundayeh language) refers to the confluence of the Sia and Padas rivers. ${ }^{1}$ This village is considered one of the last remaining heartlands of the Lundayehs in Sabah due to its remoteness and relative isolation from the state run administrative centres, such as those located in the coastal township of Sipitang and the city of Kota Kinabalu (Wong et al., 2007). The current estimated population of Long Pasia is 400 . The occupants of Long Pasia are mainly Christian; there are also a small number of Muslims who are stationed in the village as army border scouts and school teachers.

It is the main contention of this article that, despite its highland location and relative isolation, the village of Long Pasia has witnessed rapid environmental changes in the past three decades calling attention to the ways in which the community's identity ${ }^{2}$ is challenged. This article argues that traditional food practices are pivotal in understanding Lundayeh traditions, and furthermore that the intangible cultural heritage of traditional food practices secure and safeguard community indigeneity.

\footnotetext{
${ }^{1}$ While Hoare's PhD thesis, 'Cooking the wild: the role of the Lundayeh of the Ulu Padas (Sabah, Malaysia) in managing forest foods and shaping the landscape' (2002), gives a detailed explanation of the convergence between the two rivers, Vaz's chapter, 'Seeking Spaces for Biodiversity by Improving Tenure Security for Local Communities in Sabah' (2006), notes that the word 'Long Pasia' means 'mouth of the red river' referring to the colour of the water due to the tannin leached from littered forest leaves.

2 The word 'identity' is used as an expression of group distinction and communal membership; this article does not engage with discussions concerning identity formation.
} 




Figure 1. Location map of Long Pasia, southwestern tip of Sabah at the borders of Sabah, Sarawak, and Kalimantan. Adapted from: https://commons.wikimedia.org/wiki/File:Borneo_Topography.png

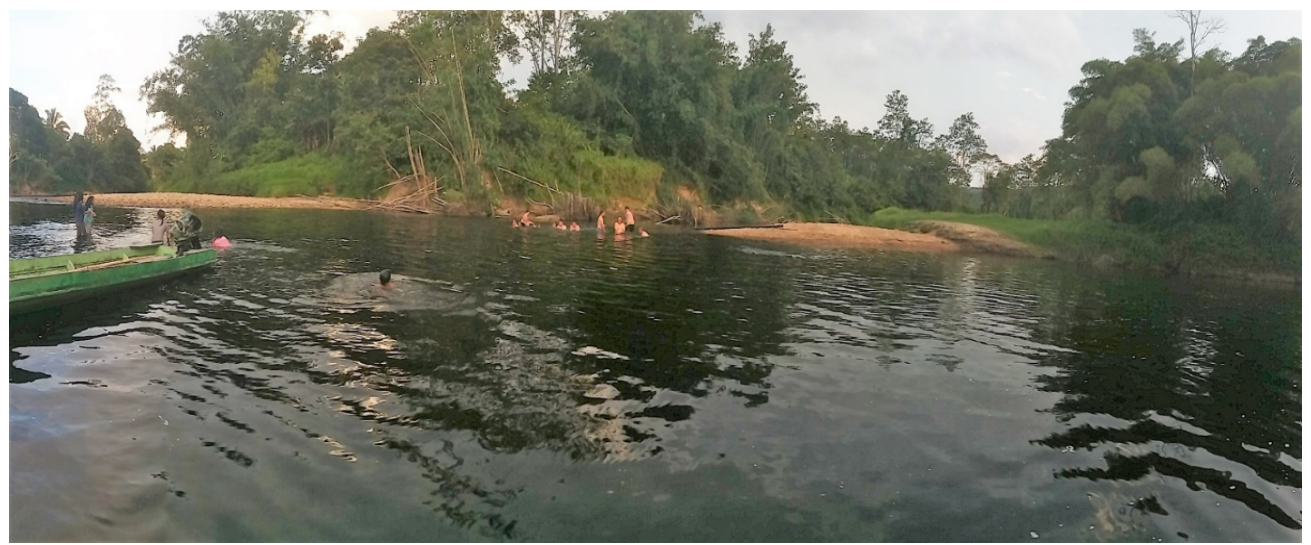

Figure 2. A view of Long Pasia showing the confluence of Padas (also known as Abpa Matang) and Sia rivers. Photograph: fieldwork August 2018.



Figure 3. A view of Long Pasia village. Photograph: fieldwork August 2018. 


\section{Lun Dayeh versus Lundayeh}

The Lundayehs are swidden agriculturalists and hunter-gatherers hence their relationship with the environment is a reflection of both their livelihood and indigeneity. The Lundayehs are believed to have originated from East Kalimantan, ${ }^{3}$ having migrated and settled along rivers as a direct result of the community's search for fertile lands for cultivation. A section of the river basin formed the village's territory which was often typified by a longhouse or several longhouses. ${ }^{4}$ This meant that, in the past, the Lundayehs' sense of belonging was closely associated with a particular longhouse or a group of longhouses within a river system rather than ethnic grouping. ${ }^{5}$ Such geographical or place-based identity prompted early researchers to regard the community through two separate words, 'Lun' (people) 'Dayeh' (upriver). As opposed to Lun Dayeh, Lun Lod means people of the lowlands, or literally, people of downriver. The term, 'Lundayeh', as we know it today, is a result of various Lundayeh sub-groups coming into contact. ${ }^{6}$ As recently as 1971 , with the joint efforts of the Lundayehs from Sabah and Kalimantan, the single word 'Lundayeh' was adopted as an ethnic category which was eventually officially accepted by the State of Sabah. ${ }^{7}$ As a land-oriented agricultural identity is central to the Lundayehs, it is worth noting that some of the community's sub-group names are drawn from farming activities such as Lun Inan Ba referring to those who cultivate wet rice fields as opposed to those who plant hill paddy and are known as Lun Tana Luun. Such evidence suggests that the river, its surrounding land, and farming activities are integral to the Lundayehs' indigeneity and sovereignty, bringing into question the extent to which environmental changes may affect the community, especially the community in Long Pasia who dwell in an isolated land area.

\section{Recent scholarship on food theory}

Although research in food studies range from its history and development to future food consumption, this article views food, and more specifically Lundayeh traditional food practices, as empirical evidence in addressing foods relation to environmental challenges in Long Pasia. While the reason to study food (Belasco, 2008), and the ways to study it, continue to expand and evolve (Miller \& Deutsch, 2009), researchers like Nicklas Neuman warn against approaching food consumption studies for purely "communicative reasons" $(2019$, p.78) where the engagement with

\footnotetext{
${ }^{3}$ See Topp (2006). p.6. Also see Harrisson, (1967) and Schneeberger, (1945).

${ }^{4}$ Crain's article, 'The Domestic Family and Long-House among the Mengalong Lun Dayeh' (1970) details the social grouping of the Lundayehs who reside in longhouses and the ways in which close domestic family ties, and at times, unrelated kinships, form cooperation in agricultural activities.

${ }^{5}$ See Deegan (1974) and Lebar (1972).

${ }^{6}$ See Crain (1978). 'The Lun Dayeh'. In Essays on Borneo Societies.

7 See Ganang (1971). 'Lundayeh luk nekukab match.' The Borneoan. Sabah College Annual School Magazine.
} 
theory becomes less significant. Neuman suggests that food studies be understood by applying social theory to explore the everyday, unreflective, and routinised consumption of food. Although to a large extent what Neuman puts forward in his article is necessary to set a clearer direction for the fast expanding studies on food and to derive new dynamics with regards to theories and practices of food consumption, this article contends that food-related researchers still need to closely consider the contextualisation of environment and culture, especially when the community identity in question is threatened. In the case study of the Lundayeh indigenous minority of Long Pasia - who self-recognise as people who live very close to nature according to the laws of nature, and who are increasingly challenged by the encroachment to their immediate surroundings - food practices constitute more than just theoretical underpinnings. In fact, food practices are a form of culture and reveal the sense of indigenous felt by members of this group. It is for this reason that this article presents empirical evidence as the main strand of investigation in line with the notion that the intangible cultural heritage of a community in transition, facing an uncertain future, needs to be ethnographically documented before the change becomes permanent, and the past way of life is completely erased from the collective imagination of its members. Moreover, the focus of this article is not merely on food but rather on the ways in which food practices are able to intervene in a situation that is otherwise uncontrollable and help in keeping the sovereignty of the community intact.

\section{Past works on the Lundayeh community in Long Pasia}

Hoare's anthropological research conducted between 1999 and 2000 during which time she lived with the villagers of Long Pasia traces the community's sustenance system through forest resources and agricultural activities; it also makes an in-depth observation regarding the community's attitude towards rapid deforestation and logging. It is worth mentioning here that from the 1980s Long Pasia was only accessible through air services which were mostly used by Flying Doctors and military border security bases, and at times by the government to provide provisions for the villagers. ${ }^{8}$ It is only as recently as 1998 that the Sabah Forest Industries Sdn. Bhd. (SFI) constructed a gravel road connecting Long Pasia to the nearest township in Sipitang District in order to transport timber. To date this non-tarmac route is used by the villagers and cuts short their travel time to 4-6hours with a four-wheel drive vehicle; the villagers used to spend 3 days by foot in the past to reach the township. Logging has also provided job opportunities to the villagers of Long Pasia who otherwise do not have access to a cash flow. Hoare's research details that, even

\footnotetext{
${ }^{8}$ There is a common notion that during the Japanese Occupation of Sabah, Long Pasia was spared due to its inaccessible location. On WWII in northern Borneo and indigenous communities see Marles et al. (2016) p.86.
} 
though the occupants of Long Pasia were discontent and at conflict with the rapid deforestation surrounding them, the idea that logging will continue and they have no power to stop it has compelled them to find new ways to adapt. The villagers have begun to use logging as a form of opportunity to gain land title as well as use the facilities provided by logging companies to clear lands for cultivation purposes. Hoare concludes (2002, p. 199):

I do not mean to give the impression that people are now in support of logging, and that they have decided to give up trying to protect their environment. A campaign to at least reduce the extent of the logging, if not stop it, is still being fought... [T] he villages [are already experiencing] a decline in water quality in the rivers among other negative impacts, such as a reduction in animal numbers and the social impact of nearby logging camps. However, people are becoming much more pragmatic, if not cynical.

At the heart of Hoare's findings is the idea that the Lundayehs continue to navigate the environmental limitations to serve their economic needs-made possible by logging and the new route-while also preserving their ancestral tradition that connects them to the land, even if it exists only at an imaginary level for the current generation. Hoare's view is shared by other researchers such as Bala (2005), who contends that the Lundayehs, in general, are open to changes and new modern values ascribing a sense of adaptability to the indigenous identity of the community.

Vaz's research, which coincides with Hoare's period of study in the late 1990s, provides a different analysis of the dynamics about the dwellers of Long Pasia. The research reveals that conservation of the forest reserve and its biodiversity is a complex issue involving the logging company, the state government, and the villagers - each with a vested interest. Vaz details that only 12,300 hectares of land was set aside for the local people and made available for native land title applications, the remainder of the Ulu Padas was concessionary to Sabah Forest Industries (SFI). This, in addition to the way the Lundayehs view their ancestral heartland in Long Pasia, resulted in a bitter conflict, not just with the government agencies and logging companies but also with fellow villagers thus prompting an inter-communal conflict. In the past, the first person who clears and cultivates can make a customary claim to a piece of land, but at present, with numerous claims to the same land made official through written applications, it is not as easy or as straightforward. Vaz's work also specifies the confrontations that the villagers have had with government agencies often resulting in unfruitful discussions. Vaz further observes that the existence of infrastructures through centralised government 
policies such as the village leadership, church, army border scouts, clinic, school, agricultural schemes, and subsidies have formalised the village of Long Pasia therefore making it more modern than a traditional Lundayeh settlement. Due to the complexity of the conflict in Long Pasia, Vaz's work (2006) concludes by proposing a call for synergetic community-conservation partnerships in order for the long-term wellbeing of the villagers and the environment to be safeguarded. ${ }^{9}$ The current fieldwork research that we conducted between 2017 and 2019 captures the changes that have occurred in Long Pasia twenty years after Hoare's and Vaz's researches were conducted. ${ }^{10}$ This article argues that, despite continuous deforestation and logging which has greatly changed the landscape of Long Pasia, through food practices - be it portrayals of food source, preparation, consumption, or waste management-the community continues to navigate the limitations posed upon them. Although logging and threats to the environment appear incontestable, the findings of our fieldwork suggest that through traditional food practices the villagers are able to retain their indigeneity and lay a claim to their Lundayeh sovereignty.

\section{Lundayeh food source: hunting}

The main ingredients of the society's diet are both hunted and cultivated; in fact, the phrase, 'lun luk tudo bang fulung' (people that live in the forest) is a common description used by the villagers in Long Pasia as a form of self-reference. Nevertheless, with a dwindling forest resource and as a direct result of deforestation, the locals have made adjustments to their hunting methods. In the past the men favoured the use of spears ('busuu') since it was a testament to their hunting skills and adult male masculinity; more importantly, it did not incur additional costs such as with the use of shotgun which required licence/rental fee and bullets. Since the younger generation is not knowledgeable or skilled in using the spear, today, the shotgun is the preferred choice of weapon. Another reason for this shift is the slimmer margin of error, thus better guaranteeing a successful hunt now that the hunters have to go further afield in order to sight prey. Moreover, the widely used 'nganup' technique in which the hunter uses a pack of dogs that runs ahead and picks up the scent of an animal to signal to its owner, increases the likelihood of securing a catch. The cash flow made available to the occupants of the village through job opportunities at the logging company and nearest city provides avenues to obtain, as well as maintain, a shotgun. More importantly, the shift to using a shotgun also marks the infrequency of the hunting trips; a hunter may go deep into the forest when he has at least two or more days to spare or when he is

\footnotetext{
${ }^{9}$ Also see Doolittle (2005).

${ }^{10}$ We spent about a month in the village of Long Pasia. Our Graduate Research Assistants made frequent visits to help obtain the materials and crosscheck the data that were required during the course of this project. We engaged the community by conducting focus group discussions, interviews, and fieldwork observations.
} 
accompanied by tourists/outsiders during which time returning empty handed is regarded as wasted energy. Shotguns give a higher probability of successfully catching prey.



Figure 4. A hunter preparing for a trip into the jungle using the "nganup" technique (left). Demonstrating air rifle target practice (right). Photograph: fieldwork August 2018.

The least favoured weapon is the blowgun ('efut') as it also requires additional skills to prepare the darts. The blowgun is also a reminder of the headhunting days and is considered against the Christian way of life observed by the villagers in Long Pasia. It has to be kept in mind that hunting is so entwined with the Lundayehs' way of life that the language does not have a generic word for 'hunting', instead, specific words exists for specific techniques. Among these, the 'ngabang' (to hunt at night by ambushing the animal), 'ngiop' (to mimic the cry of a barking deer by sucking through a folded leaf), and 'ngilu' (to hunt at night with the use of a bright light) techniques are becoming less popular. This is due to the scarcity of certain species as well as the thinning of the forest foliage that make these hunting techniques dangerous. However, 'nganup', 'ngilip' (to hunt with a weapon but without dogs) and 'ngelibut' (to hunt as a group) are still in practice. In fact, one or two of these methods may be merged in order to successfully catch a prey. ${ }^{11}$

The choice of hunting method invariably determines the type of game caught; however, the dishes prepared using the meat of such hunted animals have, to a large extent, remained the same. When a hunted carcass is slaughtered, no part is

\footnotetext{
11 Information gathered from a local hunter who brought our research team into the forest in August 2018; however, we were unable to secure a catch.
} 
discarded; different parts of the animal are cleaned and cut into smaller pieces according to the 'kikid' (side dish) prepared. Often to preserve the meat longer and to ensure a longer shelf life, the hunted meat is smoked ('narar') or pickled ('telu'). The way a meat dish is prepared entirely depends on the occasion for which it will be served. As an example, the entrails of an animal cannot be preserved for long hence are eaten as 'narar' while out in the forest hunting. Such internal organs are also cooked in soups to balance out the strong meaty flavour. ${ }^{12}$ On the other hand, the meat dish cooked for eating at home is a simple stir-fry as opposed to the one prepared for consumption at the field houses which will usually be skewered or smoked. Since the temperature in Long Pasia has become warmer, pickled meat that is kept in a 'rubih' (jar) is ladled out and heated up just before consumption which was not the case in the past. Another delicacy that continues to find its place in the Lundayeh diet is 'luba rinagas' (rice cooked with hunted wild boar lard). Indeed, some elders in Long Pasia claimed that the fat from the lard provided a creamy taste and chewy texture to the dish. Hunted meat is also used to prepare 'biter' (rice porridge) for people who are ill or convalescing, or to simply give a boost of energy. Even though the type of meat available today ranges from large games such as wild boar to smaller animals like monkeys, birds and squirrels, the way a dish is prepared is still quite traditional; for instance, an old-style pot ('lanjang') that withstands heat and a wooden spatula ('gugo') is used when preparing 'biter'. These food preparation methods that display the Lundayeh palate concerning hunted meat can be regarded as the community's defense against a rapidly changing environment prompting the President of the Dayak Lundayeh Kalimantan to state the following: "when culture is preserved, nature is preserved". ${ }^{13}$

One major intervention to the meat dishes prepared in Long Pasia is through the way store bought as well as slaughtered animals are handled. Although none of these meat sources are wasted, the esteem given to hunted meat, as opposed to slaughtered livestock and store bought meat, may be traced to the way the latter two are prepared and adapted. Livestock—buffalos, pigs, and chicken-which are not as highly regarded as hunted animals, are nowadays frequently included in the diet to replace the insufficient supply of hunted meat. In the past, buffalos and pigs were only slaughtered for weddings and feasts ('irau') since they were often given as bride price ('furut'). Furthermore, slaughtering such animals meant ample supply of meat and would have been a waste unless a particular situation warranted it. Even more significantly, slaughtering an animal also meant that a customary law had been

\footnotetext{
12 During our interview some older men said that the meaty flavour of the hunted meat represents "the smell of the jungle" and was therefore exquisite. They added that store bought meat will never be able to replace the taste of such hunted meat.

${ }^{13}$ Interview conducted in Sipitang in conjunction with the celebration of Irau Rayeh Lundayeh on 30 March 2019. The Irau Rayeh Lundayeh celebration mainly involves preparing, and feasting on, traditional Lundayeh dishes and portrays how food is an important cultural marker for the community that keeps their indigeneity alive.
} 
defied and the perpetrator was held liable for punishment where a livestock financed by him such as pig or buffalo was slaughtered ('sagit') (Romut et al., 2016). The situation is somewhat reversed today; a large animal such as the buffalo is slaughtered not just to mark an important occasion in which all villagers participate, but also to accommodate the religious sensitivities of the Muslim minority who are stationed in Long Pasia as border scouts and school teachers. Slaughtering and meat preparation is done by the Muslim men in accordance to their faith before the rest of the meat is equally shared between the villagers. The distributed buffalo meat is cooked in soups or, in complete contrast to the Lundayeh diet, in curries. Spices and curries are not part of the society's food tradition and such transformation shows significant acculturation. During the course of our fieldwork we noticed that most households had Indian curry powder packets and one woman of the house explained to us that curry is now an important part of the Lundayeh diet, especially for slaughtered meat like buffalo and store bought chicken; to quote her, "it suits the current international (anyone or anything) taste bud". In order to understand the Lundayehs' treatment of meat sources, one woman in particular gave us the following two recipes for the same soup dish, one prepared using hunted meat and the other, slaughtered meat: ${ }^{14}$

\section{Soup (hunted meat)}

1. In a pot, bring water to a boil.

2. Add garlic and ginger.

3. Add meat and boil until meat is tender.

4. Add salt/flavouring and serve.

\section{Soup (slaughtered meat)}

1. Sauté onion, garlic, ginger, and meat with oil.

2. Place the lid on; allow the meat to absorb the aroma from onion, garlic, and ginger.

3. Add water and spices wrapped in a small piece of cloth (Bouquet garni - "Sup Bunjut").

4. Boil until meat is tender.

5. Add salt/flavouring and serve.

The simplicity in the preparation of the hunted meat explains the Lundayehs' relationship with the land. In other words, the meat obtained from a hunting expedition is already tasty and does not require much work; the forest has made it sufficiently palatable. It also has to be noted here that traditionally the Lundayehs used 'affa' leaves to flavour their dishes since salt was not easily available; this was especially the case for those in the Long Pasia highland. The dwellers of this village traded paddy with salt at the nearest 'tamu' (village market), but it was a difficult journey to undertake as they had to travel by foot so the villagers often resorted to using the leaves that were easily available in the forest. This meant that hunted meat soup flavoured with 'affa' leaves had a distinctive taste and is still regarded as one

\footnotetext{
${ }^{14}$ Even though fish is an important source of protein in the Lundayeh diet, and is an important study as the river in Long Pasia has undergone various environmental changes, we have limited the scope of this paper to hunted and slaughtered meat.
} 
unique among the occupants of Long Pasia. Nevertheless, salt packets have replaced the use of the 'affa' leaves today (easily available due to the logging route). Also, the villagers often use monosodium glutamate (MSG) or other flavourings to enhance the taste of their cooking since the source of the main ingredient they use today has changed. ${ }^{15}$

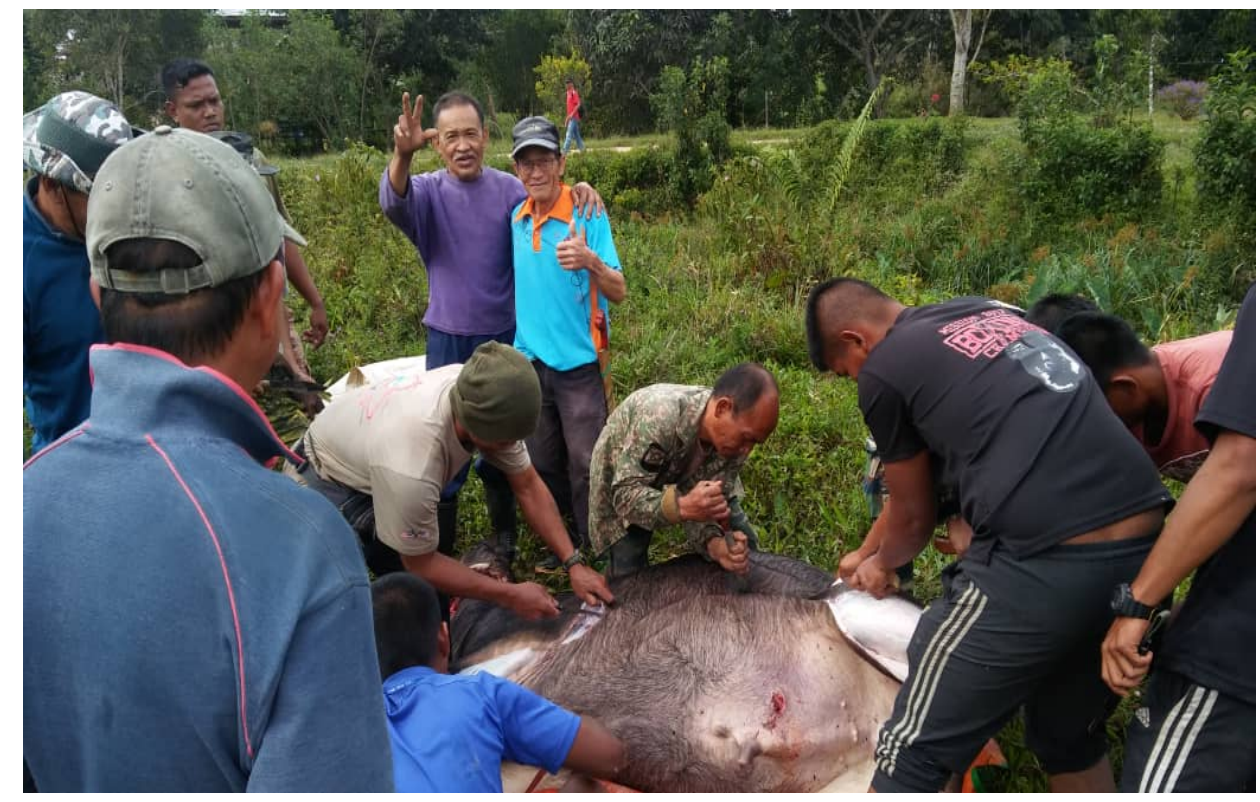

Figure 5. Slaughtering of a buffalo by Muslim border scouts for a communal 'irau'. Photograph: fieldwork August 2018

\section{Lundayeh food source: foraging}

The gathering of 'affa' leaves as a flavouring property constitutes a very small part of the community's foraging activity. ${ }^{16}$ In the past, leaves were also gathered as ingredients to prepare a dish, to wrap a cooked dish, in some cases to serve a dish, and at other times, as lids to cover pickled dishes. Some wild vegetables such as 'bawing' were so versatile that they were either boiled on their own or boiled with fish for the distinctive forest/river fragrance to emerge in the dish. 'Baku', 'itip', and 'terabak' were used to wrap soft-rice dishes to preserve the taste as well as the shelf life. Leaf-wrapped foods were also more feasible to bring to the agricultural fields. 'Baku' also had another role that it was used during the 'ngiop' hunting technique mentioned earlier, as the leaf was folded like a whistle and blown to mimic the cry of

\footnotetext{
${ }^{15}$ Dishes prepared from chicken wings and the consumption of fast food is more common nowadays since it is easier for anyone stopping by at the nearest town to get such store bought items. We have not included a discussion on this due to the focus of this paper that concentrates on traditional food practices.

${ }^{16}$ Besides gathering leaves from the forest, the Lundayehs also collect wild fruits, seeds, flowers, shoots, and the bark of various trees.
} 
a barking deer. On the other hand, a certain type of 'terabak' leaf was used as 'attap' roofing when times were difficult. ${ }^{17}$ Some other leaves like 'tarap' were even used with soil/sand to resemble a sponge in order to scrub cooking pots. Certain leaves were gathered specially to suit the Lundayeh palate and cooking methods. 'Abi' leaves, for instance, were not used when they were fresh; instead, they were dried above the cooking hearth ('tetel') before being added into the soup. Young leaves of some tapioca species were used in porridge or boiled in a soup while the mature leaves were used as lids to prevent moulds in pickled dishes.

At present, however, the rapidly disappearing forest area has affected the community's foraging activity. We noticed the following changes: (i) only during special occasions such as wedding celebrations, is food served or wrapped in a traditional manner highlighting that, the once foraged leaves, at present, have become cultural symbols and therefore have acquired an aesthetic value; and, (ii) in order to compensate the lack of wild vegetables in their diet, the villagers of Long Pasia cultivate edible plants or simply depend on store-bought vegetables and their cooking methods for plant-based dishes have shifted from boiling to stir-frying. Even though the act of gathering, or in this case, the collection, of certain types of leaves has changed due to the scarcity of particular species in the forest, the functionality of the leaves remain in the collective cultural imagination of the people. This is why during one of our visits to the nearest 'tamu' in Sipitang Town, we noticed certain species of leaves-for example, 'daun irik'-sold for the purpose of wrapping traditional Lundayeh dishes. Although these leaf species were different from the original ones that were foraged in the jungle, they have been specifically cultivated to continue the tradition of wrapping Lundayeh dishes for special celebrations. Even though such plant cultivation, as opposed to foraging, has somewhat changed the Lundayeh hunter-gatherer practice, the idea that certain traditional dishes have to be wrapped continues to shape the Lundayeh indigenous identity.

\section{Lundayeh food source: paddy cultivation}

Paddy cultivation is another connection that the Lundayehs have established for centuries with the land. Rice has long shaped the culinary tradition and identity of these people. The Lundayehs eat rice meals three times a day, in fact, rice-based dishes such as 'luba' laya" (soft rice wrapped in leaves), 'luba' urag' (boiled rice), 'luba' rinagas' (rice cooked with boar lard), 'biter' (rice porridge cooked solely with forest vegetables or solely with meat), and desserts like 'pinaram' (deep-fried rice flour cakes), 'kelupis' (rice cakes wrapped in leaves and steamed), 'fadey mo"' (sticky rice) and 'kui' (assorted sweet and savoury rice cakes either steamed or fried) are

\footnotetext{
${ }^{17}$ Information gathered from Bua' Udan, the oldest woman in Long Pasia during our fieldwork in August 2018.
} 
central to the Lundayeh diet. It is not unusual to serve rice as a main meal with another rice-based 'kikid' (side dish). As a matter of fact, similar to hunted meat, cultivated rice is treated with high esteem because it represents the relationship that the community has secured with the land from one generation to another. Moreover, for the community in Long Pasia, the variety of the rice grain planted in the village is not found elsewhere. The Adan rice, according to the locals, has a unique texture and taste due to the soil and 'red water of the Sia River'. ${ }^{18}$
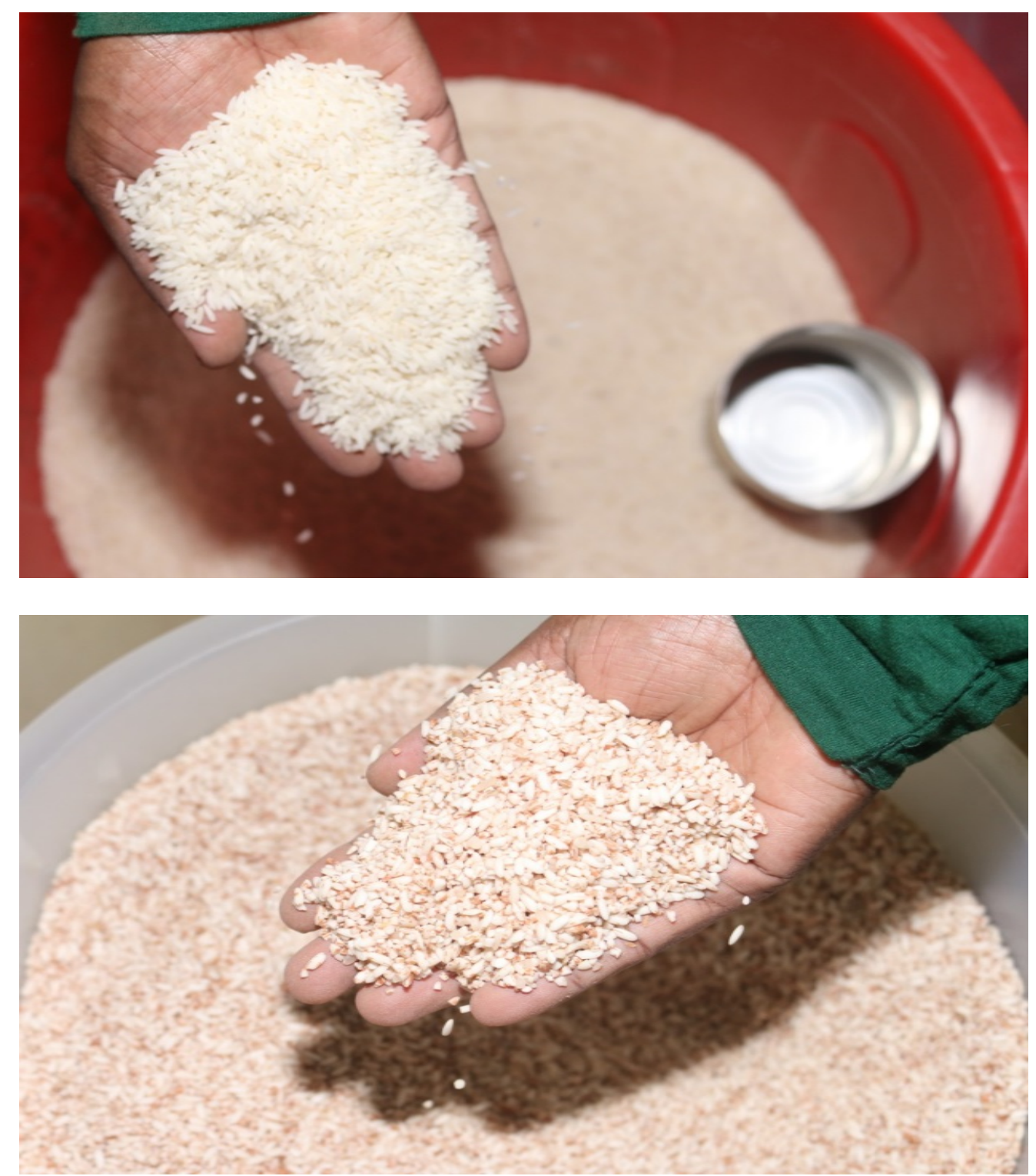

Figure 6. Some of the rice varieties cultivated in Long Pasia.

Photograph: fieldwork August 2018.

18 Wong et al. (2007, p. 641) use the term "pade Adan atau beras Bario" (Adan paddy or Bario rice) to describe that this variety may have a shared origin. 


\section{Food-related cultural value: agricultural cooperative work}

Despite its central role in the Lundayeh diet and seeming distinctiveness, paddy cultivation is not just about food production. It is a cultural marker, through which the occupants of Long Pasia are able to revisit a past tradition to re-engage with their sense of communalism. This is because, in the past, the Lundayeh way of life was interwoven with living in the longhouse; the cooperative relationships between the members of the longhouse was mainly expressed through shared farming activities such as paddy cultivation. Due to the spread of Christianity and the colonial perception that living in the longhouse created increasing problems to the community, these traditional dwelling structures were eventually abandoned. The longhouse, which was built on stilts, had its own cultural significance; two in particular are worth noting: (i) the folks of a longhouse shared a very strong sense of kinship that was displayed through the sharing of meat, farming activities, and communal feasting; and (ii) the dwellers had a zero wastage principle which contributed to their method in disposing of leftover food. When the dwelling structure changed from living in the longhouse to living in individual houses, as is the case in Long Pasia, numerous longhouse-related cultural values disappeared. Nevertheless, through 'gotong royong' (shared farm work) at the paddy field, the very essence of the longhouse kinship continues to survive, albeit at a smaller scale. ${ }^{19}$ Janowski (1987) notes that the practice of 'gotong royong' replaced a previous system of worksharing known as 'ngerufen' and that the change was encouraged by the church. This was due to the agricultural feasts that were held after 'ngerufen' which often involved the drinking of rice wine or 'burak'. Since drinking burak was intoxicating and often caused the Lundayeh men to engage in unnecessary fights, the church intervened and forbade the consumption of 'burak' altogether. ${ }^{20}$ Today, through paddy cultivation, even though the atmosphere of 'ngerufen' has changed ('burak' has been replaced by hot and cold beverages), its principle has continued to survive as demonstrated through shared farming activities in Long Pasia. This is an important point to note because the divisive individual housing system, and the decline in meat-sharing due to scarcity of large game, have all restricted the growth of communalism. In order for communalism and kinship to survive in the environmentally threatened Long Pasia, shared farming activities are not only necessary but also timely.

\footnotetext{
${ }^{19}$ Crain (1970) notes that the shift from hill paddy to wet paddy cultivation changed the communal structure of shared farming since the former required more hard labour encouraging better sense of communalism. Most families in Long Pasia have resorted to wet paddy cultivation due to the numerous problems faced in hill paddy cultivation, some of which are directly related to rapid logging. See Crain (1970) 'The Megalong Lun Dayeh LongHouse'. Hoare's thesis traces a similar shift, see 'Cooking the wild'(2002), pp.64-70.

${ }^{20} \mathrm{See}$ 'The Motivating Forces Behind Recent Changes in the Wet Rice Agricultural System in the Kelabit Highlands'. Sarawak Gazette.
} 
Additionally, two other important communal markers, those of socialisation and shared feasting between members of the village, also continue to thrive during farming. This also explains the reason why some rice-based dishes like 'luba' laya' are still wrapped in leaves; its origin is traceable to communal farming activities where soft rice in wrapped leaves was easy to for workers to bring to the field house. As a matter of fact, at present, 'luba' laya' is often served during 'irau' (feasts) or any other communal function, to mark the identity of the Lundayeh people because the dish is associated with a particular way of life regarded exclusive to the community. These forms of food evidence highlight that even with the absence of the longhouse the Lundayehs are able to re-connect with their traditional values through foodrelated practices as they reflect their sense of an 'imagined community' ${ }^{21}$ in connection with the land.

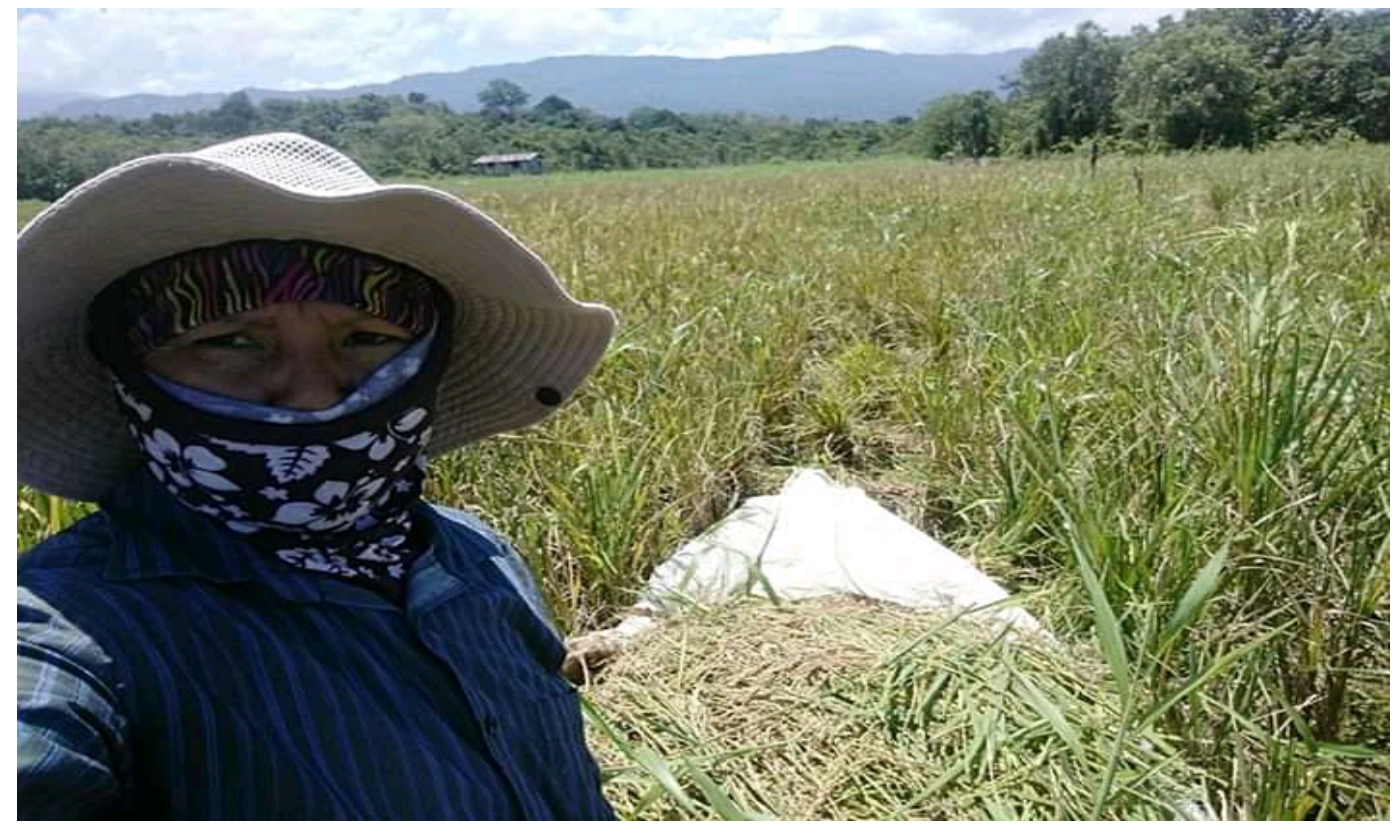

Figure 7. A Lundayeh lady in Long Pasia during the harvest of paddy in her field. Photograph: fieldwork August 2018

Even though most of the villagers in Long Pasia have shifted from hill paddy to wet paddy cultivation due to the scarcity of suitable land nearby (also caused by rapid logging), the coming together of the locals for farming-related activities have resulted in a complementary work schedule in relation to hunting. Paddy is only planted and harvested once a year in the village. This is mainly because the occupants have made adjustments to their paddy cultivation and hunting trips so that one does not interfere with the other. For instance, during the fruiting season of the forest more hunting activities are carried out while the women do menial work in the paddy fields.

\footnotetext{
${ }^{21}$ According to the political scientist, Benedict Anderson, 'an imagined community' refers to a group of people who may not know one another, yet, in their imagination they exist as a whole community due to the sovereign geographical boundaries they share $(1983$, p.15).
} 
Conversely, when there is harvesting work at the field, hunting activities are limited. This means that the dwellers in Long Pasia cultivate paddy according to their needs and keep the stock all year round; rice supply is complemented with hunted or trapped meat. Moreover, the local wisdom that the land has to be given the opportunity to restore its minerals is so strongly followed in Long Pasia that, after a harvest, the land is left untouched to ensure its long-term sustainability; livestock such as buffalos are allowed to roam freely in order for the dung to fertilise the paddy field until the next weeding and planting cycle resumes.

\section{Religiously sensitive food adaptation practices}

Modernisation can take many forms; in particular, this last section explores the role of religion as a catalyst for modernity. The findings of our fieldwork suggest that the Lundayehs recognise their indigeneity through food practices in relation to religious change which they have come to embrace in Long Pasia. In order to understand the interplay between modernity, Lundayeh food practices and religion, it is crucial to understand the changing religious identity involving the community. The Lundayehs in Long Pasia are predominantly Christians, but the point that should be crucially noted here is that they are also religiously adaptive. While the Lundayeh people converted to Christianity in the $1930 \mathrm{~s}^{22}$ they did not become religiously observant until the 1970s. For example, while drinking alcohol is not technically forbidden in Christianity, the Christian missionaries successfully convinced the people to associate drinking with $\sin ^{23}$ Now that drinking is religiously prohibited, there also seems to be a strong sense of social pressure to keep the prohibition of 'burak', thus keeping the socio-religious fabric intact in Long Pasia.

Although the people in Long Pasia have fully embraced the Christian way of life, which is institutionally centred at the Borneo Evangelical Church, ${ }^{24}$ to what extent some pre-Christian beliefs and practices survived can be explained through the centrality of the crocodile in Lundayeh mythology. In the past, the Lundayeh people practiced a ritual called 'nui ulung' which included the erection of the 'ulung buayeh'-an earthen crocodile mound that was erected to celebrate the warriors who had successfully hunted enemy heads. This is because, to the Lundayehs, the crocodile is a powerful ferocious animal that is able to survive both on land and in water; a successful Lundayeh headhunter therefore symbolically represents the traits of the animal and is greatly revered. The 'nui ulung' celebration was specifically held

\footnotetext{
${ }^{22}$ For a useful overview on the history of Christianity in Long Pasia, see Samporoh (1999), and Topp (2006).

${ }^{23}$ For a detailed account of how Christian missionaries changed some of the traditional habits or practices among the Lundayeh, see for example, Shirley Lees (1979).

${ }^{24}$ For a more detailed account on how Christianity is institutionally important to the Lundayeh people in Long Pasia, see, for example, Karulus \& Radzi (2010, pp. 107-116).
} 
to celebrate such success. Since headhunting was neither compatible with the Christian worldview nor with the colonial government's administration, both 'nui ulung' and 'ulung buayeh' were abolished. Ganang et al. (2018) detail the historic and cultural significance of the crocodile to the Lundayeh people and make a claim that the importance of crocodile to the community's indigenous identity continued to remain long after they migrated from East Kalimantan to other parts of Borneo. By using the evidence derived from Lundayeh oral literature, Ganang et al. explain that even when the community settled in highlands like Long Pasia, which is nowhere near the habitat of crocodiles, the image prevailed in their collective imagination to the extent that any events associated with the Lundayeh culture would most likely include a symbolic representation of the animal. More importantly, in recent years, since efforts to recreate the crocodile in the form of concrete cement structures in Lundayeh settlements have failed due to religious constraints, the incorporation of the crocodile image into food form is significant.



Figure 8. Example of a crocodile mound (ulung buayeh) traditionally built to commemorate a successful headhunting expedition. Source accessed 16 October 2019 https://www.penangfoodforthought.com/2018/12/mari-mari-cultural-village.html

'Luba' buayeh' (literally, 'crocodile rice') is rice arranged in such a way that it resembles a crocodile. It has to be kept in mind that 'luba' buayeh' is put together not for its taste, but rather for its distinctive appearance and creative design. This is why the "luba" is mainly made of boiled white rice; nonetheless the preparation and display, depending on the size, may take hours to complete. The creativity in constructing the "luba" depends on the accessibility and availability of ingredients that are common to the Lundayeh culture and environment. Conscious effort is given to make the rice display as lifelike as possible. The meat that is stuffed inside the stomach of the 'luba" determines whether it is 'halal'. Since our stay in Long Pasia 
coincided with the visit of a political dignitary, both 'halal' and 'non-halal' 'luba' buayeh' were prepared for the communal 'irau'. In the course of the preparation for the 'irau' and during the 'irau' itself, an interesting interplay between the Lundayeh people's religious identity and the Muslim guests' dietary restriction was observable. The buffalos were slaughtered and cooked according to Islamic law, but the prayer to bless the gathering and meal was performed by a Christian Pastor in the Malay language.

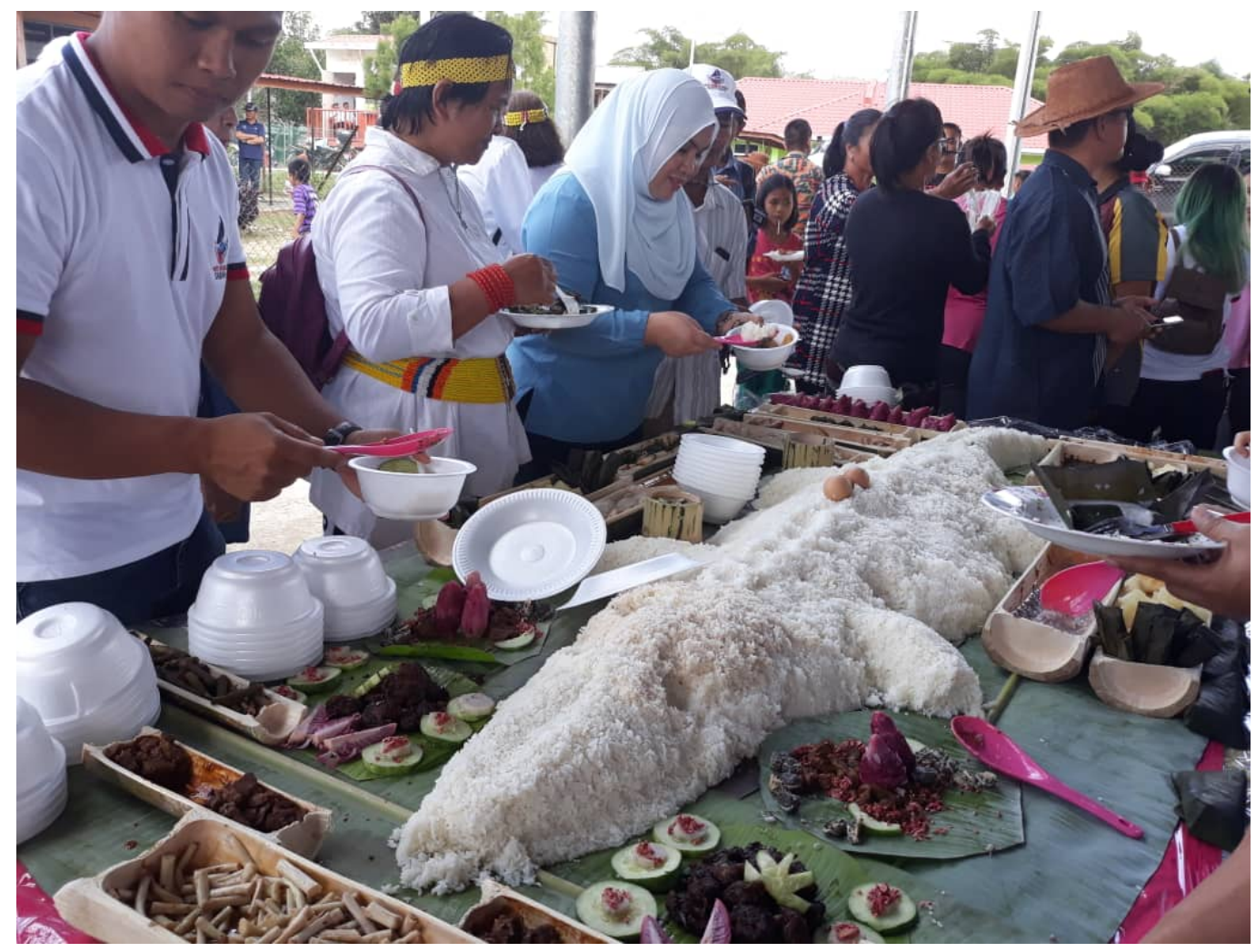

Figure 9. A halal' luba' buayeh' (that replaces the practice of building 'ulung buayeh') served at a communal 'irau'. Photograph: fieldwork August 2018.

The non-halal 'luba", prepared using the most important Lundayeh ingredient, wild boar meat, demonstrates how the community has managed to navigate the Christian prohibitions by transferring the values associated with 'nui ulung'/'ulung buayeh' to the making of the crocodile rice. Furthermore, when preparing another 'luba" by using buffalo meat that has been slaughtered according to the Islamic religious faith, the Lundayeh food adaptation method seemed to have negotiated another limitation, adjusting in accordance to Malay-Muslim religious sensitivity. These adjustments show that the Lundayehs continue to embrace change while at the same time remaining devoted to their indigenous identity. 


\section{Conclusion}

It is undeniable that the Lundayehs face challenges in terms of a rapidly changing environmental landscape and religious modernization, forcing them to adapt and adjust accordingly. In this article, we argue that despite these changes and challenges the Lundayehs continue to retain their indigeneity through traditional food practices, even though in some instances these practices only live on in spirit. We realised during our fieldwork that the younger generation simply observe their ancestral food habits without truly knowing the underlying philosophy that intricately connects them to the land, the forest and nature. Notwithstanding, the current aspects of food culture in Long Pasia are reflective of past communal memories which engender and maintain a historical consciousness crucial to the survivability of the community's indigenous identity.

More importantly, in this article we have traced, redefined, and reevaluated traditional Lundayeh food practices to demonstrate how the villagers of Long Pasia can maintain their native agency and assert their sovereignty in spite of increasing environmental challenges. We began by tracing modified hunting techniques in Long Pasia which highlight the villagers' coping strategy in relation to fast disappearing tropical forestry lands. Additionally, the attitude towards hunted meat remains the same because traditional cooking recipes are still used to prepare a meat dish to capture the distinctive smell and taste of the forest. We then discussed foraging by referring particularly to certain leaf species and their uses in traditional Lundayeh diet; our explanation included present cultivation, as opposed to past foraging of plant sources, but stressed that the Lundayeh practice of wrapping ricebased dishes in leaves continues to prevail in the community's culinary practice. Following this, we included a section on agricultural cooperative work that continues to survive in a modified form where the people in Long Pasia have shifted from hill paddy to wet paddy cultivation because there is a scarcity of land and manpower due to continuous logging activity as well as abandonment of the longhouse dwelling structure. As another form of coping mechanism, the villagers maintain, to a significant degree, a structured work schedule between hunting and farming so that one practice does not interfere with the other. The feasting celebrations that follow the agricultural cooperative work also continue in a modified form where alcoholic drinks, which were in practice in the past, are now replaced by non-alcoholic hot and cold beverages. At the heart of such cooperative work communalism and kinship are preserved so that the Lundayehs' sense of togetherness, which has been severely threatened with the abandonment of longhouse dwelling, can continue to safeguard the community's identity. Lastly we looked at the ways in which religiously adaptive foods help the Lundayehs to navigate very sensitive religious constraints while continuing to preserve the indigenous cultural values associated with headhunting. 
Our main argument in this article is that an indigenous consciousness can prevail in the collective imagination of its people through adapted and modified traditional food practices, even as the surrounding environment that used to shape their indigeneity continues to erode. Such an understanding, we feel, is necessary when addressing the concerns of other endangered indigenous communities facing similar constraints. In fact, we believe that traditional food practices may serve as interventionist mechanisms in situations where a community's core values and identity are threatened by deforestation, and furthermore, maintaining the intangible cultural heritage of food practices can act to sustain and revive indigeneity. 


\section{References}

Anderson, B. (1983). Imagined Communities: Reflections on the Origins and Spread of Nationalism. Verso.

Bala, B. (2005). Menyingkap Perubahan Sosial di Kalangan Masyarakat Lun Bawang. MANU, Jurnal Pusat Penataran IImu \& Bahasa, 10, 15-36.

Belasco W. (2008). Food: The Key Concepts. Berg.

Crain, J.B. (1970). The Megalong Lun Dayeh Long-House. Sarawak Museum Journal, 18, 169-185.

Crain, J.B. (1970). The Domestic Family and Long-House Among the Mengalong Lun Dayeh. Sarawak Museum Journal, 18, 186-192.

Crain, J.B. (1978). The Lun Dayeh. In V.T. King (Ed.) Essays on Borneo Societies (pp.123142). Hull Monographs on Southeast Asia No.7. Oxford University Press

Deegan, J.L. (1974). Community Fragmentation Among the Lun Bawang. Sarawak Museum Journal, 22(43), 229-247.

Doolittle, A.A. (2005). Property and Politics in Sabah: Native Struggles over Land Rights. University of Washington Press.

Ganang, R.Y. (1971). Lundayeh luk nekuab match. The Borneoan. (pp. 128-130). Kota Kinabalu: Sabah College Annual School Magazine.

Ganang, R.Y., Wong, J.K.L. \& Ganesan, K. (2018). Representation of Buayeh in the Quality of Life of the Lundayeh People. Malaysian Journal of Social Sciences and Humanities (MJSSH). 3(2), 169-184.

Harrisson, T. (1967). Ethnological Notes on the Muruts of the Sapulut River, Sabah. Journal of the Malaysian branch of the Royal Asiatic Society, 40, 111-129.

Hoare, A. (2002). Cooking the Wild: the role of the Lundayeh of the Ulu Padas (Sabah, Malaysia) in managing forest foods and shaping the landscape. [PhD Dissertation]. University of Kent: Department of Anthropology.

Janowski, M. (1987). The Motivating Forces Behind Recent Changes in the Wet Rice Agricultural System in the Kelabit Highlands. Sarawak Gazette. CXIII, (1504),9-20.

Karulus, Y., \& Radzi, M.S.M. (2010). Agama dan Kepercayaan Kaum Ludayeh Long Pasia. In I. Ali \& B.B. Basrah Bee (Eds.). Long Pasia (pp.93-118). UMS Press.

Lebar, F.M. (Ed). (1972). Ethnic Groups of Insular Southeast Asia, Vol. 1: Indonesia, Andaman Islands, and Madagascar. Human Relations Area Files Press.

Lees, S. (1979). Drunk Before Dawn. OMF Books.

'Long Pasia' Retrieved 20 June 2020 https://commons.wikimedia.org/wiki/File:Borneo Topography.png.

Marles, J.E., Jukim, M., \& Dhont, F. (2016). Tropical War Stories: Preserving Oral Histories from WWII Borneo. eTropic: electronic Journal of Studies in the Tropics 15 (2), 8294. DOI: https://doi.org/10.25120/etropic.15.2.2016.3544

Miller, J., \& Deutsch, J. (2009). Food Studies: An Introduction to Research Methods. Berg Publisher.

Neuman, N. (2019). On the engagement with social theory in food studies: cultural symbols and social practices. Food, Culture \& Society, 22:1, 78-94. DOI https://doi.org/10.1080/15528014.2018.1547069

Romut, J., Sading, D.J., \& Jamiyan, F. (Ed). (2016). Inventori Budaya Etnik Negeri Sabah: Etnik Lundayeh. Kota Kinabalu, Sabah: Lembaga Kebudayaan Negeri Sabah, Kementerian Pelancongan, Kebudayaan dan Alam Sekitar.

Samporoh, R. (1999). Sejarah Gereja Sidang Injil Borneo. Edisi Khas Sempena Ulang Tahun SIB ke-40. Kuala Lumpur: Nipuhawang Publishing.

Schneeberger, W.F. (1945). The Kerayan-Kelabit Highlands of Central Northeast Borneo. The Geographical Review, 35, 544-562. 
Topp, L. (2006). The Lundayeh of Long Pasia and Long Mio: Their History and Legends. Denmark: WWF.

Ulung Buayeh. Retrieved 16 October 2019 from https://www.penangfoodforthought.com/2018/12/mari-mari-cultural-village.html

Vaz, J. (2006). Seeking Spaces for Biodiversity by Improving Tenure Security for Local Communities in Sabah. In F.M. Cooke (Ed.). State, Communities and Forests in Contemporary Borneo. [Asia-Pacific Environment Monograph 1]. Australian National University Press. http://doi.org/10.22459/SCFCB.07.2006

Wong, J.K.L., Bala, B., \& Bee, B.B.B. (2007). Masyarakat Lundayeh di Sabah: Satu Kajian Asal Usul, Migrasi dan Klasifikasi Etnik. Pemuliharaan Sejarah dan Tamadun Borneo Ke Arah Pengukuhan Negara Bangsa (pp. 637-652). Pusat Sejarah Brunei, Kementerian Kebudayaan, Belia dan Sukan.

\section{Acknowledgements}

The authors of this article are part of the SDK0019-2017 research project funded by Universiti Malaysia Sabah. We would like to acknowledge the contribution of Ricky Yakub Ganang who was our primary guide and informant throughout the course of this research.

Kavitha Ganesan is a Senior Lecturer at Universiti Malaysia Sabah and has been primarily working on Malaysian Literature in English with a particular interest in female life-writings. Her current research interest is in areas related to postcolonial indigenous studies.

Anantha Raman Govindasamy is an Associate Professor in politics at the Center for the Promotion of Knowledge and Language Learning, Universiti Malaysia Sabah. His research area focuses on Malaysian and Southeast Asian politics. He has contributed to journals such as the Australian Journal of International Affairs and Asian Journal of Political Science.

Jane Wong Kon Ling (Ph.D. Linguistics) is a lecturer at the Centre for the Promotion of Knowledge and Language Learning of Universiti Malaysia Sabah. She teaches Meanings in the Contexts of Communication. Her research and publication interest covers the native languages of Sabah and the Malay dialect of Sabah.

Shaffarullah Abdul Rahman is a Senior Lecturer at Centre for the Promotion of Knowledge and Language, Universiti Malaysia Sabah. Dr. Shaffarullah completed his Ph.D. at Monash University. His main research focuses on religious diversity at the intersection between politics, philosophy, and religion. His current research is mainly on the issues concerning trans-border indigenous culture. He has also 
collaborated actively with researchers in several other disciplines of literature, politics, and linguistics.

Kennedy Aaron Aguol's (Cert. Food Processing Technology [Fermentation Tech], Diploma of Agriculture Science [Mycology], Bachelor of Fishery Science [Aquaculture], Master of Science Biotechnology [Microalgae Biotechnology]) area of expertise is Microalgae Biotechnology, Aquaculture Live Feed \& Food Production. His research interests are Functional Feed, Microalgal Biotechnological innovation, communication for food security development, indigenous heritage food production, indigenous food mycology and fermentation, and indigenous self-sufficiency using Aquaponic from renewable energy.

Jamsari Bin Hashim's (Bachelor of Human Sciences [Communication], Master of Social Sciences [Communication Management]) area of expertise is media. His research interests are technological innovation, communication for development, traditional media, social media, and public relations. He is pursuing a doctoral study in media.

Bilcher Bala (Ph.D. History) is a lecturer at the Faculty of Humanity, Art, and Heritage of Universiti Malaysia Sabah. He conducts lectures on American History. His research and publication interest covers Peace Corp in Malaysia and History of Brunei, Sabah and Sarawak. 